\title{
Quantification of waves in lidar observations of noctilucent clouds at scales from seconds to minutes
}

\author{
N. Kaifler, G. Baumgarten, J. Fiedler, and F.-J. Lübken \\ Leibniz Institute of Atmospheric Physics at the Rostock University, Kühlungsborn, Germany \\ Correspondence to: N. Kaifler (n.kaifler@iap-kborn.de) \\ Received: 13 December 2012 - Published in Atmos. Chem. Phys. Discuss.: 20 March 2013 \\ Revised: 31 October 2013 - Accepted: 4 November 2013 - Published: 4 December 2013
}

\begin{abstract}
We present small-scale structures and waves observed in noctilucent clouds (NLC) by lidar at an unprecedented temporal resolution of $30 \mathrm{~s}$ or less. The measurements were taken with the Rayleigh/Mie/Raman lidar at the ALOMAR observatory in northern Norway $\left(69^{\circ} \mathrm{N}\right)$ in the years 2008-2011. We find multiple layer NLC in $7.9 \%$ of the time for a brightness threshold of $\delta \beta=12 \times 10^{-10} \mathrm{~m}^{-1} \mathrm{sr}^{-1}$. In comparison to $10 \mathrm{~min}$ averaged data, the $30 \mathrm{~s}$ dataset shows considerably more structure. For limited periods, quasimonochromatic waves in NLC altitude variations are common, in accord with ground-based NLC imagery. For the combined dataset, on the other hand, we do not find preferred periods but rather significant periods at all timescales observed ( $1 \mathrm{~min}$ to $1 \mathrm{~h}$ ). Typical wave amplitudes in the layer vertical displacements are $0.2 \mathrm{~km}$ with maximum amplitudes up to $2.3 \mathrm{~km}$. Average spectral slopes of temporal altitude and brightness variations are $-2.01 \pm 0.25$ for centroid altitude, $-1.41 \pm 0.24$ for peak brightness and $-1.73 \pm 0.25$ for integrated brightness. Evaluating a new single-pulse detection system, we observe altitude variations of $70 \mathrm{~s}$ period and spectral slopes down to a scale of $10 \mathrm{~s}$. We evaluate the suitability of NLC parameters as tracers for gravity waves.
\end{abstract}

\section{Introduction}

Gravity waves (GW) mostly propagate from tropospheric sources throughout the layers of the atmosphere and play an important role in atmospheric dynamics (Staquet and Sommeria, 2002; Fritts and Alexander, 2003). Breaking GW at mesospheric or thermospheric altitudes drive the meridional circulation by momentum and energy deposition, with large effects on the thermal structure (Holton, 1983). The breaking process leads to a transition to turbulence, inducing the formation of layered structures (Fritts et al., 2003). Such transitions were for example observed by Yamada et al. (2001) in hydroxyl $(\mathrm{OH})$ airglow and modeled in 3-D by Fritts et al. (1997). Turbulence in the mesopause region is intensely studied (e.g. Fritts et al., 1988; Blix et al., 1990; Lübken, 1997; Müllemann et al., 2003; Rapp et al., 2004). In summer, it is discussed regarding its relevance to polar mesospheric summer echoes (PMSE) (Balsley et al., 1983; Hoppe et al., 1990; Kelley et al., 1990; Hill et al., 1999; Lübken et al., 2002; Rapp and Lübken, 2004). Small-scale structures in the mesosphere-lower thermosphere (MLT) region are attributed either directly to GW or to instabilities associated with GW breaking. The presence of such structures have been known since the early observations of noctilucent clouds (Jesse, 1885; Leslie, 1885; Backhouse, 1885). NLC are ice clouds that form in the low summer temperatures of the mesopause region and by their sensitive dependence on ambient conditions depict the thermal state of this remote area. Horizontal wavelengths down to $10 \mathrm{~km}$ have been derived from groundbased photography (Witt, 1962). So-called NLC bands of typically $50 \mathrm{~km}$ horizontal wavelength are thought to be direct manifestations of GW, and the shorter-wavelength billows, at about $5-10 \mathrm{~km}$, that are often oriented orthogonally to bands can be caused by localized Kelvin-Helmholtz (KH) instabilities (Fritts et al., 1993). Figure 1 shows two NLC images displaying various wave structures. Today, NLC are observed from satellites, then termed polar mesospheric clouds (PMC), by networks of ground-based cameras and by several lidar stations at middle and polar latitudes. Chandran et al. (2009) found GW signatures below $50 \mathrm{~km}$ horizontal wavelength in PMC in the polar region using the CIPS instrument onboard the AIM satellite. Pautet et al. (2010) characterized 
NLC structures of 30 events obtained by ground-based cameras in Sweden, finding wavelengths of $25-30 \mathrm{~km}$ and periods of $10-30 \mathrm{~min}$. A study by Dalin et al. (2010) revealed KH waves and horseshoe-shaped structures in NLC that were used to infer turbulent diffusion rates.

Small-scale structures in the mesopause region are also known from tracers other than NLC (Gardner and Taylor, 1998). Ripple structures similar to those seen in NLC were observed by $\mathrm{OH}$ airglow instruments (Hecht, 2004). Observations of $\mathrm{OH}$ airglow require darkness, which limits observation time to winter at high latitudes or nighttime at low latitudes. Nielsen et al. (2009) presented a wave climatology obtained from $\mathrm{OH}$ airglow during two Antarctic winters, finding horizontal wavelengths between 15 and $40 \mathrm{~km}$ and periods of 6-12 min the most common. A high-resolution study of these ripples finding short periods between 2 and 4 min was conducted by Hecht et al. (2007) at a low latitude. Those structures have shorter periods than the Brunt-Väisälä period, which is about $5 \mathrm{~min}$ at these altitudes and the lower boundary for coherent GW. Shorter periods are attributed either to dynamical or convective instabilities (Fritts et al., 1997). KH instabilities were also observed in the sodium layer using a sodium fluorescence lidar at midlatitudes in summer (Pfrommer et al., 2009). Power spectral densities of altitude series of sporadic sodium layers were retrieved down to a scale of seconds with a sodium lidar at high latitudes in wintertime by Tsuda et al. (2011). Wavelike structures are also known from PMSE, a radar phenomenon often observed in conjunction with NLC (e.g. Hoppe and Fritts, 1995; Klekociuk et al., 2008). Combined studies with lidar, radar and cameras were presented by Taylor et al. (2009) and Baumgarten et al. $(2009,2012)$ and are complicated by the requirement of daylight-capable instruments. Additionally, studies of instabilities or turbulence require high spatial and/or temporal resolution.

In this paper, we present a new dataset of the ALOMAR Rayleigh/Mie/Raman (RMR) lidar, consisting of 30 s resolution measurements of NLC, and evaluate it with respect to small-scale waves that become visible in altitude and brightness variations of NLC. So far, statistics of NLC with this instrument are based on 14 or $10 \mathrm{~min}$ profiles (Fiedler et al., 2009; Kaifler et al., 2013). NLC characteristics from other instruments are evaluated at $12 \mathrm{~min}$ or $1 \mathrm{~h}$ resolution (e.g. Wickwar et al., 2002; Chu et al., 2006). Here, we concentrate on waves in NLC revealed at the highest possible temporal resolution of $30 \mathrm{~s}$ that was achieved during the years 2008-2011. We also show results from a new single-pulse detection system acquired in 2011, allowing power spectral densities to be analyzed down to a scale of seconds. We cover the vertical structure of NLC layers as well as the temporal evolution of cloud parameters.

\section{Instrument}

We use data of the ALOMAR Rayleigh/Mie/Raman lidar located in northern Norway $\left(69.29^{\circ} \mathrm{N}, 16.01^{\circ} \mathrm{E}\right)$ at a $30 \mathrm{~s}$ resolution that are available from 2008. For NLC research, we use $532 \mathrm{~nm}$ wavelength laser light produced by two Nd:YAG lasers of about $400 \mathrm{~mJ}$ pulse $\mathrm{s}^{-1}$ energy with $30 \mathrm{~Hz}$ repetition rate. The return signal is recorded by two steerable $1.8 \mathrm{~m}$ diameter Cassegrain telescopes. The instrument is normally operated using two lidar beams in different directions (used for wind retrievals; Baumgarten, 2010). For $20^{\circ}$ off-zenith beams the advected measurement volumes of about $10 \mathrm{~m}$ diameter are separated by $\approx 40 \mathrm{~km}$ at NLC altitudes. Together with an average wind speed of $44 \mathrm{~m} \mathrm{~s}^{-1}$ and $30 \mathrm{~s}$ temporal resolution the measurement volume is expanded to $1.3 \mathrm{~km}$ in the direction of the wind speed; therefore, we can consider measurements by both beams as independent. The instrument is described by von Zahn et al. (2000) and has been used for NLC research since 1994. We refer to Fiedler et al. (2009) for decadal statistics of NLC and details of the analysis method, for instance error estimations.

In the NLC seasons 2008-2011, NLC measurements at $30 \mathrm{~s}$ temporal and $40 \mathrm{~m}$ vertical resolution are available on 171 days. In total, $2303 \mathrm{~h}$ of measurements were collected (909 h with the North-West-Telescope, NWT, and $1393 \mathrm{~h}$ with the South-East-Telescope, SET). Significant NLC are detected given $\beta(z, t)>\Delta \beta(z, t)$, where $\beta(z, t)$ is the volume backscatter coefficient per time $(t)$ and altitude $(z)$ in units of $10^{-10} \mathrm{~m}^{-1} \mathrm{sr}^{-1}(\beta(z, t)$ is termed brightness in the following) and $\Delta \beta(z, t)$ the $1 \sigma$ measurement uncertainty. The data are smoothed by a binomial filter of $112 \mathrm{~m}$ width in the vertical. To remove single false detections, $36 \%$ significant signal in a $750 \mathrm{~m} \times 2.5 \mathrm{~min}$ neighborhood is required. We extract three parameters per profile that are suited for time series analysis, namely the centroid altitude $z_{\mathrm{c}}$ calculated from the weighted brightness profile, the absolute peak brightness $\beta_{\text {peak }}$ and the column-integrated brightness $\beta_{\text {int }}$ :

$$
\begin{aligned}
& z_{\mathrm{c}}(t)=\frac{\sum_{z} z \cdot \beta(z, t)}{\sum_{z} \beta(z, t)} \\
& \beta_{\text {peak }}(t)=\max \beta(z, t) \\
& \beta_{\text {int }}(t)=\sum_{z}(\beta(z, t) \cdot \Delta z),
\end{aligned}
$$

with $\Delta z=37 \mathrm{~m}$ (compare also Kaifler et al., 2013, for analysis of 10 min data of this dataset). To evaluate the maximum possible temporal resolution of this lidar system, a lidar single-shot acquisition (LISA) unit was installed in 2011 which is capable of counting backscattered photons from single laser pulses. The range resolution is $25 \mathrm{~m}$ between 41 and $91 \mathrm{~km}$ altitude and the time resolution is $33 \mathrm{~ms}$, corresponding to the laser pulse repetition frequency of $30 \mathrm{~Hz}$. The data analysis applied to LISA data are explained in Sect. 3.3. 

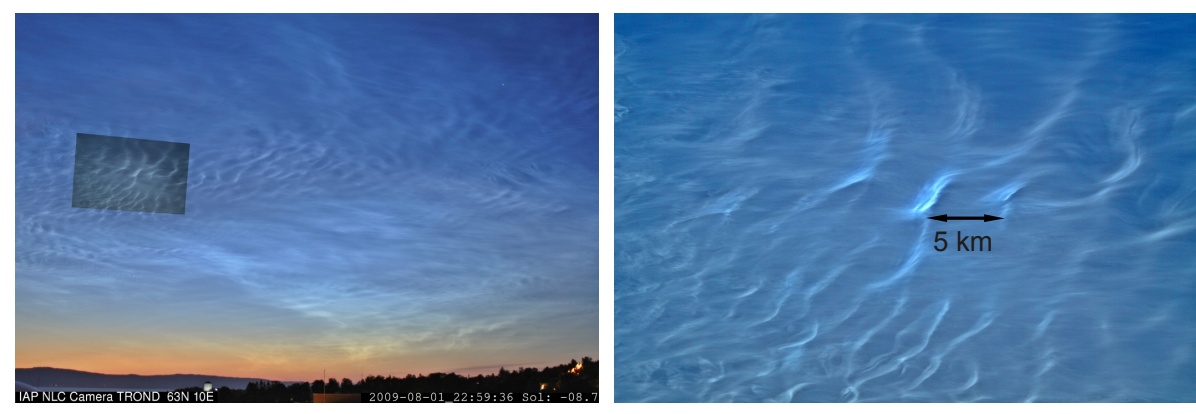

Fig. 1. Observation of a NLC from Trondheim $\left(63.4^{\circ} \mathrm{N}\right)$ on 1 August 2009, 23:00 UT. Left: using a camera with a wide field of view $\left(47^{\circ} \times 31^{\circ}\right)$. Right: high-resolution image with a camera using a narrow FOV (marked by grey box in left picture). Structures are enhanced by a 2-stage local contrast filter (similar to Baumgarten et al., 2009). The horizontal dimensions of the high-resolution FOV are about $50 \mathrm{~km} \times 88 \mathrm{~km}$.

\section{Data analysis}

This section is structured as follows: in Sect. 3.1, the transition from the $10 \mathrm{~min}$ to the $30 \mathrm{~s}$ high-resolution dataset is discussed and evaluated especially with regard to vertical structure, since this is important for extracting suitable parameters for time series analysis. Section 3.2 starts with the presentation of waves in temporal altitude variations and subsequently uses different methods to characterize these waves. The methods chosen here are (1) the quantification of relative altitude variations by means of residuals and standard deviations to assess typical wave amplitudes; (2) the time derivative of altitude variations; and (3) wavelet analysis of $z_{\mathrm{c}}, \beta_{\text {peak }}$ and $\beta_{\text {int }}$ variations for spectra from which significant periods are derived. Section 3.3 concludes this part by evaluating the maximum possible time resolution of our instrument using a newly installed single-shot detection system.

\subsection{Vertical structure}

Figure 2 (middle) shows a $3 \mathrm{~h}$ NLC measurement from 25 July 2010 with pronounced wave motions and small-scale structures visible in the $30 \mathrm{~s}$ resolution dataset (360 profiles). We read periods of altitude variations between 15 and $20 \mathrm{~min}$ with amplitudes of about $400 \mathrm{~m}$ from the figure. A variety of smaller-scale coherent structures, for example around 22:00 UT, and vertical layering, for example at 21:00 UT and at 22:30 UT, is visible. We also note that an overturning structure is observed around 21:25 UT. To demonstrate the improvement we show the same measurement at $10 \mathrm{~min}$ resolution which was used by previous analysis methods of NLC lidar data of this instrument (Fig. 2 top). The wave motion is faintly outlined; however the detailed structures can only be seen in the high-resolution dataset. Although generally the signal-to-noise ratio improves for averaged data, the study of small-scale waves requires high temporal and spatial resolution. The reduction of integration time therefore makes it possible for the first time to resolve these smaller- scale structures. Height profiles with waves or structures at smaller scales resolved at a high temporal and spatial resolution deviate significantly from the average (Fig. 2 bottom). This also influences parameters of the standard analysis. For example, the maximum brightness of a layer can be larger and at a different altitude due to fluctuations that would otherwise be averaged out. This is an indication of the existence of smaller-scale waves.

To assess the vertical structure of the high-resolution profiles we apply a similar method as used by Hoffmann et al. (2005) for radar data of PMSE. Relative peaks in the brightness profile $\beta(z)$ are determined by zero crossings of the derivative. These local extrema are selected as local layer maxima if they are above the surrounding brightness values by at least $\delta \beta=12 \times 10^{-10} \mathrm{~m}^{-1} \mathrm{sr}^{-1}$. That means that a single peak is at least $\delta \beta$ high. Between two accepted peaks, the minimum brightness value is at least $\delta \beta$ lower than the lower brightness of both peaks. This method differs from previous studies, which required absence of NLC between layers. A single peak or the highest peak corresponds to $\beta_{\text {peak. }}$ In Fig. 2 (middle), the detected relative peaks are marked by black dots. The datasets (30 s resolution) from both telescopes were analyzed. The percentage of two or more layers compared to all NLC profiles is $7.9 \%$ for $\delta \beta=12 \times 10^{-10} \mathrm{~m}^{-1} \mathrm{sr}^{-1}$. Lowering the threshold to $\delta \beta=4 \times 10^{-10} \mathrm{~m}^{-1} \mathrm{sr}^{-1}$ yields multiple peaks in $33.8 \%$ of all NLC.

For time series analysis it is important to extract parameters that represent the NLC layer and the motion in a suitable and robust way. In the case of pronounced vertical structure (multiple layers), it is for example not advisable to extract peak altitudes as the time series might exhibit steps. This would be unrealistic and make the time series unsuitable for spectral analysis. To minimize this influence, we choose the centroid altitude $z_{\mathrm{c}}(t)$ for further analysis, as this better represents the average motion of the layer. 

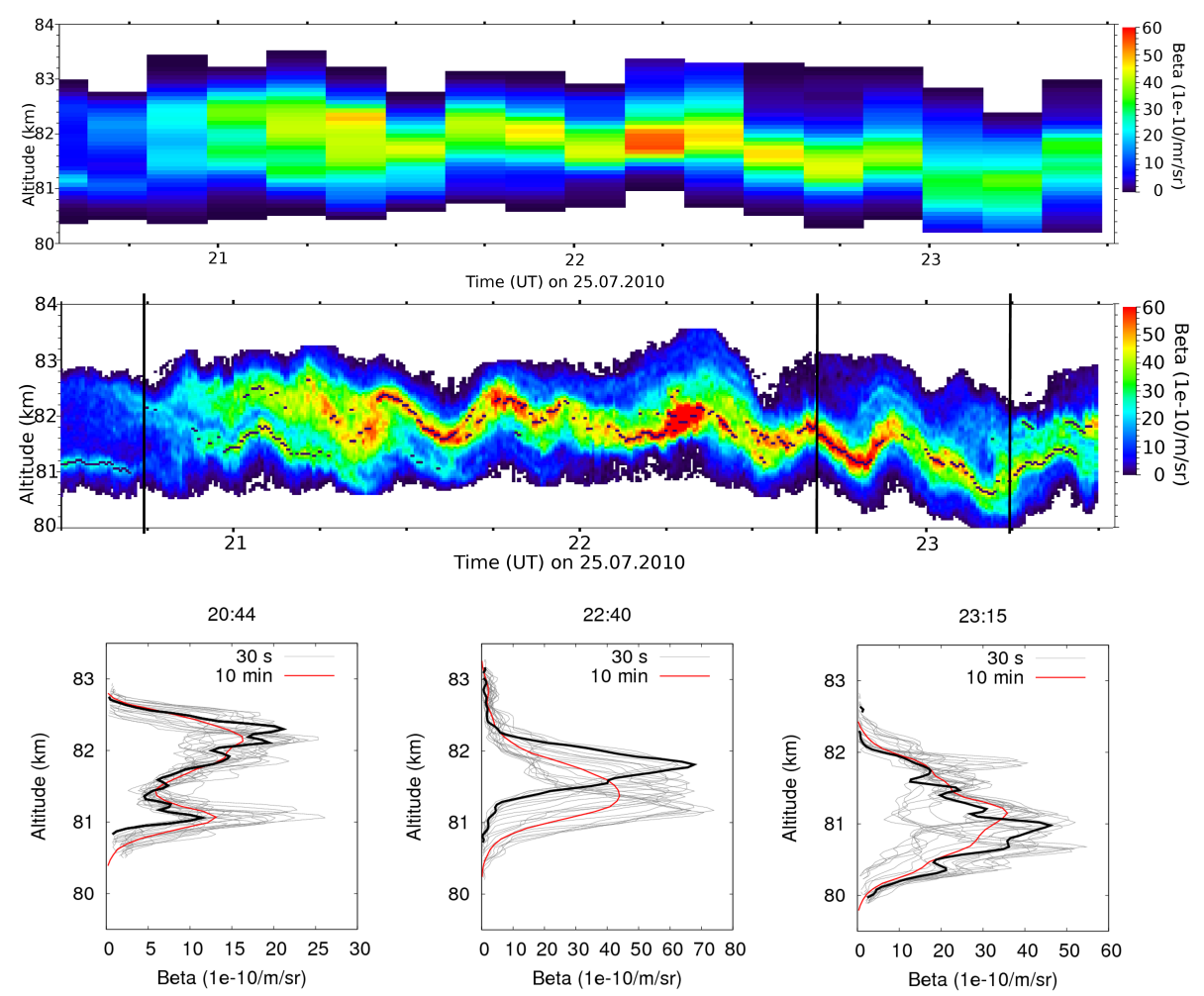

Fig. 2. Three hours of NLC observation on 25 July 2010, by the ALOMAR RMR lidar (SET) with 10 min resolution (top) and with $30 \mathrm{~s}$ resolution (middle). Detected layers are marked by black dots (threshold $\delta \beta=12 \times 10^{-10} \mathrm{~m}^{-1} \mathrm{sr}^{-1}$; see text for details). Bottom: comparison of vertical profiles with $10 \mathrm{~min}$ and $30 \mathrm{~s}$ resolution at 20:44, 22:40 and 23:15 UT, as marked in the high-resolution plot by vertical lines. The 30 s profiles contributing to the $10 \mathrm{~min}$ smoothed profile are shown in grey, the one at the exact time given in black. Note the different $x$ axis scaling.

\subsection{Temporal evolution of single layers}

Figure 3 shows all continuous time series of $z_{\mathrm{c}}(t)$ longer than $0.5 \mathrm{~h}$ as a function of altitude and time of day. The dataset consists of 291 such time series, corresponding to $461 \mathrm{~h}$, which are $55 \times 10^{3}$ records. Time series were split when changes of $z_{\mathrm{c}}(t)$ larger than $0.5 \mathrm{~km}$ during $30 \mathrm{~s}$ occurred, indicating the emergence of another ice layer at a different altitude. This criterion led to the truncation of 15 and the splitting of six time series. To reveal the wave motions superposed on a linear motion a linear trend $f(t)=z_{0}+c\left(t-t_{0}\right)$ was removed. In the plot, peak-to-valley variations up to $3 \mathrm{~km}$ can be seen (e.g. upper right corner). Typical amplitudes are on the order of $0.5 \mathrm{~km}$. To quantify this wave motion, we calculate the residuals as

$\delta_{z_{\mathrm{c}}}(t)=\left|z_{\mathrm{c}}(t)-f(t)\right|$

for each data point. By measuring the deviation from a linear motion, $\delta_{z_{\mathrm{c}}}(t)$ corresponds to a wave signal, in a sense. Low values of $\delta_{z_{\mathrm{c}}}$ will be most common and the histogram will decrease for higher values, which correspond to the maximum wave amplitude. Indeed, the histogram of all $\delta_{z_{\mathrm{c}}}$ decreases monotonically by about $0.5 \mathrm{~km}$ per decade (Fig. 4 top). The maximum residual found was $2.3 \mathrm{~km}$. This analysis was carried out profile by profile. To represent the average wave motion per time series we calculate the standard deviation

$\sigma_{z_{\mathrm{c}, n}}=\sqrt{\frac{1}{\left(i\left(t_{1}\right)-i\left(t_{0}\right)\right)} \sum_{i=i\left(t_{0}\right)}^{i\left(t_{1}\right)}\left(z_{\mathrm{c}}(i)-f(i)\right)^{2}}$,

for each time series $n$ where the index $i$ runs from the beginning $t_{0}$ to the end $t_{1}$ of the respective time series. This event mean deviation is a measure for the wave activity, where low values resemble linear motions and higher values denote wave motions with large amplitude. The histogram of $\sigma_{z_{c, n}}$ peaks at $0.2 \mathrm{~km}$ and extends to $0.75 \mathrm{~km}$, with most values between 0.05 and $0.4 \mathrm{~km}$ (Fig. 4 bottom). We find few time series with very low wave activity.

Large residuals are actually caused by wave-like motions and not distortions, for example caused by noise, of the time series. This can be seen from the example dataset shown in Fig. 5 (top). The temporal evolution of the time series is now assessed by means of a derivative. The numerical derivative was calculated by an adaptive central difference algorithm using initial step sizes of $2.5,4.5,10.5$ and $20.5 \mathrm{~min}$ (Galassi et al., 2009). This corresponds to smoothing the 


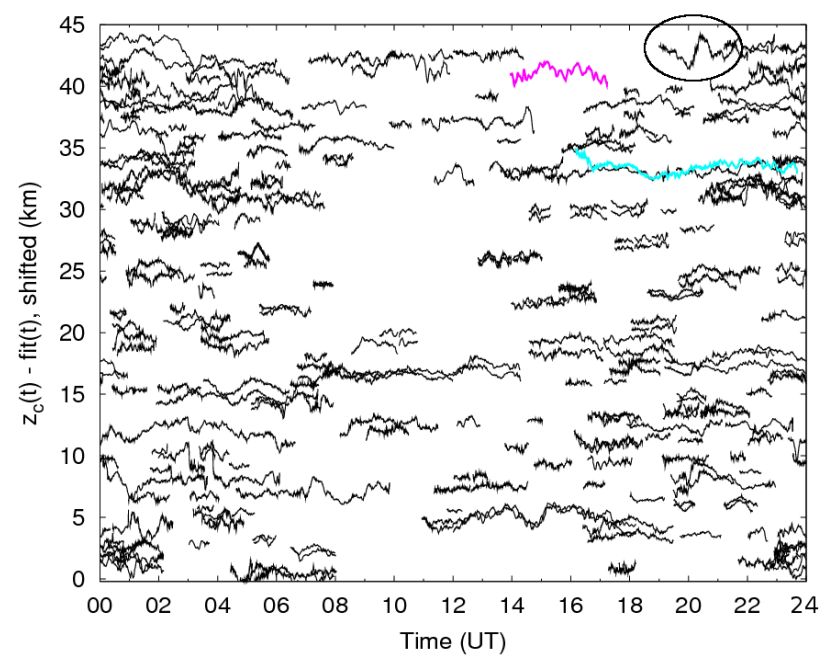

Fig. 3. Time series $z_{\mathrm{c}}(t)$, shown as a function of time of day for all years 2008-2011 and both telescopes. A linear trend was removed. Only measurements longer than $0.5 \mathrm{~h}$ are included (in total 291 time series). For better visualization, the baseline of the curve was shifted upwards in altitude for each NLC measurement. The two examples discussed in more detail in this paper are shown in color (19 July 2011 in pink, 25 July 2010 in light blue).

time series. A derivative calculated in a $20.5 \mathrm{~min}$ window is not sensitive to shorter-period variations, and therefore the value of the derivative is lower (the slope is flatter), while using a shorter window will allow for steeper slopes of either sign and the value will be higher (Fig. 5 bottom). That way, by using different time windows, we estimate the temporal vertical layer variations at different timescales. The distribution of derivatives derived from the same dataset as used before ( $461 \mathrm{~h}$, linear fit removed) is shown in Fig. 6 . For the largest time window of $20.5 \mathrm{~min}$ the distribution is indeed narrowest, corresponding to the observations of low absolute values only, with a standard deviation of $2.5 \mathrm{kmh}^{-1}$ ( $0.7 \mathrm{~m} \mathrm{~s}^{-1}$ ). At shorter timescales of $2.5 \mathrm{~min}$, the symmetrical distribution widens to $8.0 \mathrm{kmh}^{-1}$ ( $\widehat{=} 2.2 \mathrm{~m} \mathrm{~s}^{-1}$ ). The widening of the distribution indicates that waves at scales smaller than 20.5 min exist.

Spectral analysis of time series of altitude or brightness variations allows two main questions to be answered: first the average slope of all spectra is indicative of an underlying power law, but on the other hand a peak in a single spectrum is a sign of a prominent quasi-monochromatic wave and the method can thus be used to determine occurrence and frequency of distinct wave events.

We employ the wavelet algorithm described by Torrence and Compo (1998) using a Morlet wavelet of order 6.0. We restrict the dataset to time series longer than $2 \mathrm{~h}$, which leaves 67 time series for analysis $(238 \mathrm{~h})$. Time-averaging of the local wavelet spectrum of one time series yields a global wavelet spectrum (GWS), which was normalized to correspond to the scales of a Fourier power spectrum. The GWS of
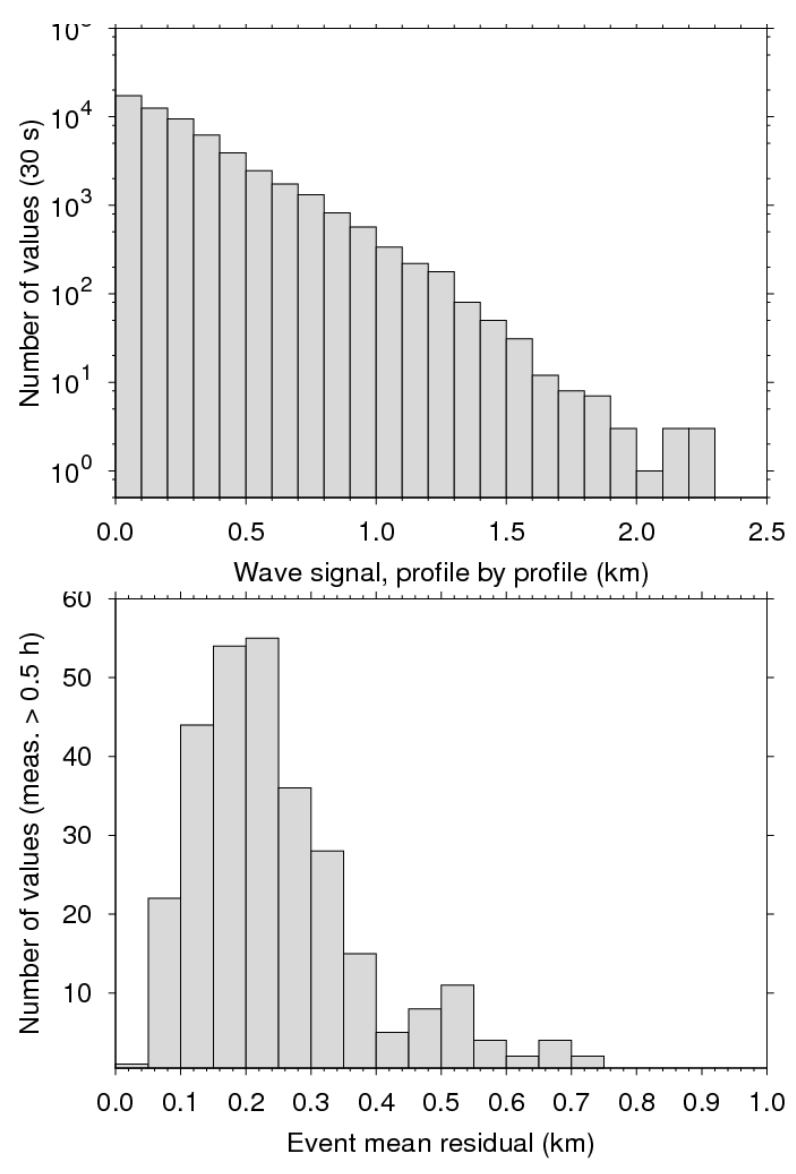

Fig. 4. Histogram of residuals (top) and standard deviations (bottom) for the same dataset as in Fig. 3 (see text for details).

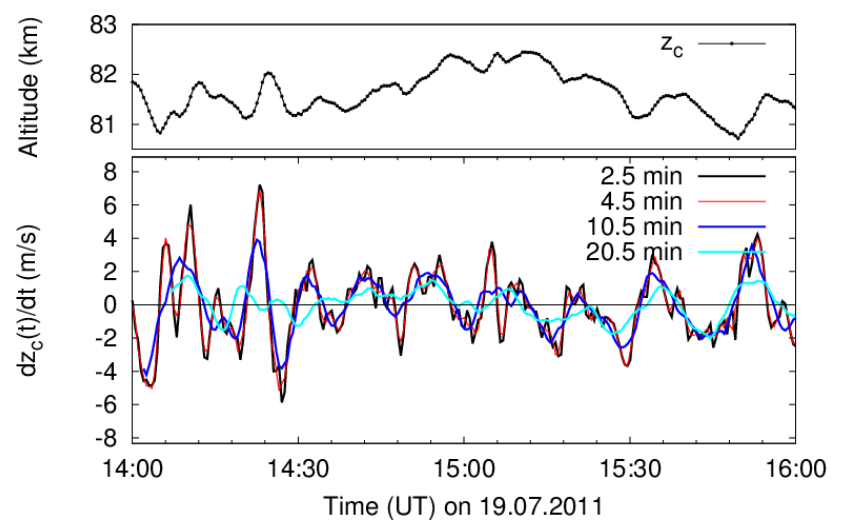

Fig. 5. Top: section of the time series $z_{\mathrm{c}}(t)$ on 19 July 2011 (SET). Bottom: derivatives using different time windows.

all time series $z_{\mathrm{c}}(t), \beta_{\text {peak }}(t)$ and $\beta_{\text {int }}(t)$ are shown in Fig. 7. The two time series selected in Figs. 2 and 5 are marked in color. The average spectral slopes $\alpha$, which are indicated as a black line below the spectra, are determined from linear fits to each spectrum. Values of $\alpha$ are given in Table 1. Spectra of $\beta_{\text {peak }}(t)$ with small slopes are found from weaker 
Table 1. Average spectral slopes $\alpha$ of time series of the NLC parameters $z_{\mathrm{c}}, \beta_{\text {peak }}$ and $\beta_{\text {int }}$. Given are the mean value, the standard deviation and the statistical error of the mean.

\begin{tabular}{lll}
\hline Spectral slope & Wavelet transform & FFT \\
\hline$\alpha_{z_{\mathrm{c}}}$ & $-2.01 \pm 0.25,0.03$ & $-1.94 \pm 0.19,0.02$ \\
$\alpha_{\beta_{\text {peak }}}$ & $-1.41 \pm 0.24,0.03$ & $-1.49 \pm 0.25,0.03$ \\
$\alpha_{\beta_{\text {int }}}$ & $-1.73 \pm 0.25,0.03$ & $-1.86 \pm 0.24,0.03$ \\
\hline
\end{tabular}

NLC (lower $\beta$ ) or from time series with rather uniform variations without large brightness bursts for example. Analyzing stronger NLC only $\left(\beta_{\text {peak }}(t)>13 \times 10^{-10} \mathrm{~m}^{-1} \mathrm{sr}^{-1}\right)$ results in 21 time series with an average spectral slope of $-1.48 \pm 0.18$. We evaluate spectra only down to a multiple of three times the resolution, i.e. down to $1.5 \mathrm{~min}$ (not the greyshaded area). To test the robustness of the results, we performed the spectral analysis also using a fast Fourier transform (FFT) algorithm. The results differ with regard to the estimated statistical error of the mean. The differences of the spectral slopes range between -0.06 and 0.13 . We estimate the precision of the analysis method (statistic and systematic) to be about 0.1 , so higher than the estimated error of the mean, but smaller than the standard deviation.

Using the significance test according to Torrence and Compo (1998) we identified locally (at certain times) and globally (throughout the whole observation period) significant periods in all spectra analyzed. These are shown as histograms in Fig. 8. To test the influence of noise we transform a time series of random numbers, too (the result is shown in shaded grey). While many periods are falsely classified as locally significant, only at the very low or high period end of the spectrum may noise contribute to the globally significant periods. Quasi-monochromatic waves are represented by peaks with a finite bandwidth. In the case of $z_{\mathrm{c}}$, we find globally significant periods in 39 out of 67 time series and count a total of 61 quasi-monochromatic waves; i.e. some time series contain more than one quasi-monochromatic wave. Considering only periods above $5 \mathrm{~min}$, we find 48 quasi-monochromatic waves in 28 out of 67 time series. For the example shown in Fig. 5 we find globally significant periods between 7.2 and $19.8 \mathrm{~min}$.

To explore the timescales shorter than $5 \mathrm{~min}$ and to evaluate the highest time resolution achievable with our current lidar system configuration, we installed a LISA unit. In the following section we will extend the spectra to scales below 1 min by analyzing raw data of this new LISA unit.

\subsection{LISA}

The lidar single-shot acquisition system (LISA) records the return signal of each single laser shot, i.e. every $33 \mathrm{~ms}$. Mostly, only one or no count is detected per altitude bin of $25 \mathrm{~m}$. On lidar profiles with such low, Poisson-distributed statistics, the standard procedure of, for example, back-

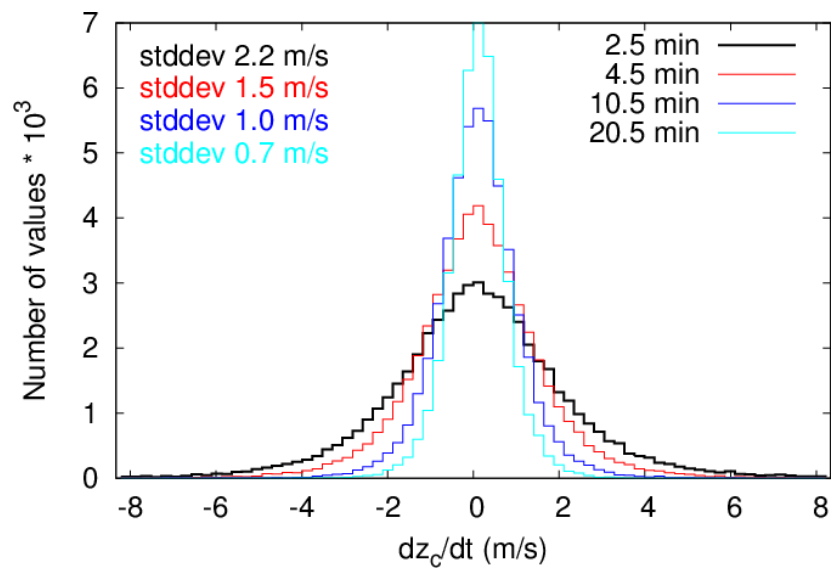

Fig. 6. Histogram of derivatives of all $z_{\mathrm{c}}(t)$ of NWT and SET, 2008-2011. The derivative was estimated using different time windows, hinting at variability at different timescales. The hours of data used are between $364 \mathrm{~h}(20.5 \mathrm{~min})$ and $451 \mathrm{~h}(2.5 \mathrm{~min})$ due to boundary effects.

ground subtraction and normalizing to a density profile cannot be performed that easily. However, the NLC layer and its motion are clearly visible in these raw data. An example dataset of $10 \mathrm{~min}$ duration (corresponding to $18 \times 10^{3}$ shots) is shown in Fig. 9 (top). Here, ten shots were summed to enhance the NLC layer in the plot. The layer exhibits variations at a scale of about $1 \mathrm{~min}$, shorter than the Brunt-Väisälä period. For a spectral analysis, we select time series with bright NLC and very low variations in atmospheric transmission. We analyze time series of 10 min length with $33 \mathrm{~ms}$ resolution in order to extend the spectrum of our previous analysis to smaller timescales. To do this, we extract the approximate motion of the NLC layer by a simple algorithm: we integrate $10 \mathrm{~min}$ of data and determine the NLC peak altitude. The 10 min data file is accepted as a NLC data file if the NLC peak exceeds 500 counts and exceeds the solar background signal that is measured between 86 and $91 \mathrm{~km}$ by a factor of 3 . Out of $252 \mathrm{~h}$ (total of $27.5 \times 10^{6}$ shots) of measurement during the NLC season 2011, we select $15 \mathrm{~h}$ of high quality (91 time series, 11 events). We now determine the centroid altitude in an altitude range of $1 \mathrm{~km}$ centered around the NLC peak and perform a wavelet transform. A duration of $10 \mathrm{~min}$ is short enough to limit the variations of atmospheric transmission. At very small timescales, we expect noise processes - solar background as well as photon-counting noise - to prevail. The global wavelet spectra shown in Fig. 9 (bottom) indeed become flat at small timescales, and the very low period end was omitted in the plot. Down to a scale of $10 \mathrm{~s}$, however, the NLC spectra show deviations from the noise spectra with slopes up to -2 . The spectrum of the selected example also shows a peak at about $70 \mathrm{~s}$, in accordance with the time series plot. We conclude that quasi-periodic variations of NLC altitude are detectable and existent down to a scale of about $10 \mathrm{~s}$. It might be possible to extend this to smaller 

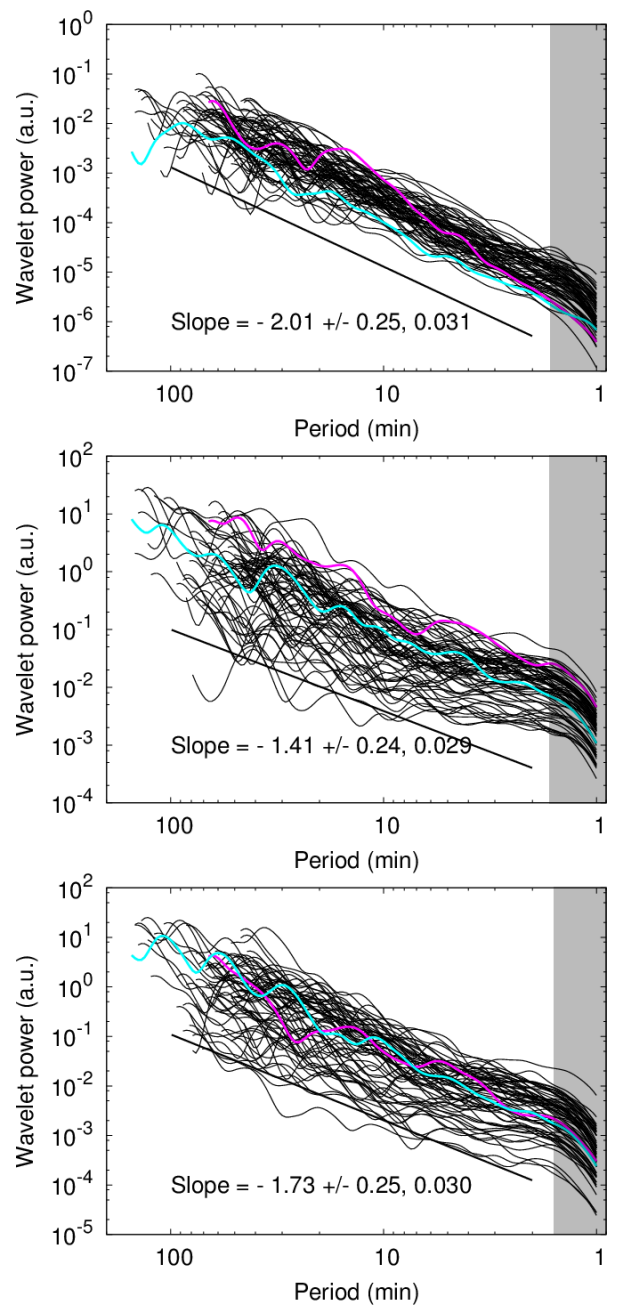

Fig. 7. Global wavelet spectra (GWS) for $z_{\mathrm{c}}(t)$ (top), $\beta_{\text {peak }}(t)$ (middle) and $\beta_{\text {int }}(t)$ (bottom). Sixty-seven (67) time series longer than $2 \mathrm{~h}$ were analyzed $(238 \mathrm{~h}$, NWT and SET). The two examples discussed in more detail in this paper are shown in color (19 July 2011 in pink, 25 July 2010 in light blue).

scales using a more sophisticated data analysis; however restrictions due to low counting statistics and noise processes cannot be avoided.

\section{Discussion}

Ground-based lidars observe NLC at a fixed location as a function of altitude and time. NLC structures, however, exist in three spatial dimensions and evolve with time. NLC are influenced by background parameters, i.e. temporal and spatial temperature changes, velocities and velocity changes that are caused for example by GW. These cause at the same time microphysical changes of NLC particles. To what extent NLC can be considered as passive tracers depends on the timescale. Although a full evaluation of microphysical

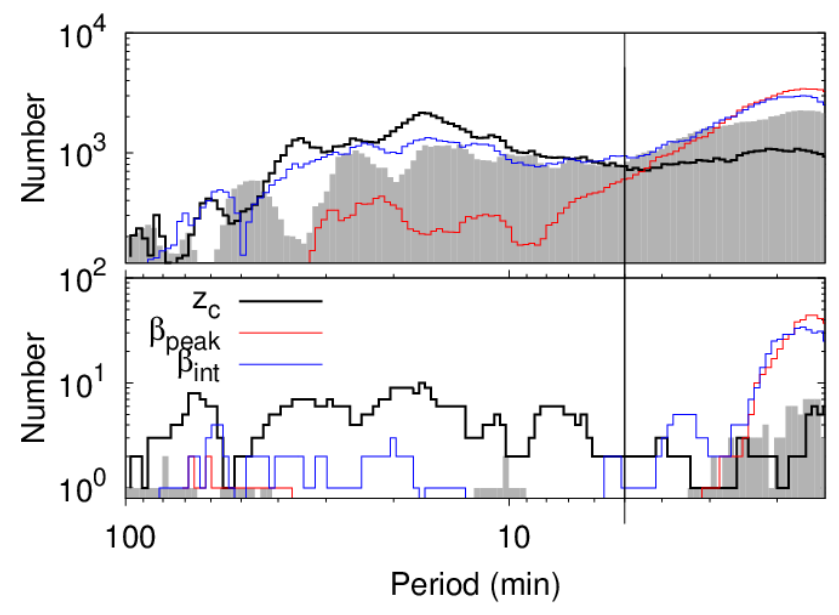

Fig. 8. Histogram of locally (top) and globally (bottom) significant periods obtained from wavelet spectra of $z_{\mathrm{c}}(t), \beta_{\text {peak }}(t)$ and $\beta_{\text {int }}(t)$. The periods from a time series of random numbers that accidentally appear significant are shown in shaded grey. The Brunt-Väisälä period of $5 \mathrm{~min}$ is indicated by a vertical line.

aspects of NLC formation is beyond the scope of this paper, we want to assess the influences of horizontal and vertical velocity and temperature variations on NLC altitude and brightness, which are the NLC parameters studied here. We will discuss our results with emphasis on the suitability of these quantities for deriving GW parameters, especially spectral characteristics, and compare with other observational techniques.

\subsection{Vertical NLC variations and the influence of temperature}

The thermal structure of the mesopause region with temperatures low enough for the formation of ice particles determines the vertical range in which NLC can exist. Model simulations show that NLC particles grow for several days before reaching sizes suitable for lidar observations (e.g. Turco et al., 1982; Kiliani et al., 2010). The $\mathrm{H}_{2} \mathrm{O}$-ice saturated zone in summer is located between about 82 and $94 \mathrm{~km}$ altitude. Large ice particles forming NLC exist at $83 \pm 1.5 \mathrm{~km}$ altitude. NLC are located at the lower $S=1$ border, i.e. close to the saturation point, which makes ice particles sensitive to ambient conditions like small temperature fluctuations. Sedimentation in Earth's gravity field and transport by vertical wind lead to quick sublimation, such that average observation times are on the order of a few hours. Inside this saturation zone, the NLC layer is modulated by GW propagating from below and breaking GW, inducing in situ generated instabilities or secondary GW waves, respectively turbulence. Similar motions are known from PMSE layers (e.g. Hoppe and Fritts, 1995). In the time domain, we observe waves with distinct periods in variations of $z_{\mathrm{c}}(t)$, for instance of $15 \mathrm{~min}$ period and $400 \mathrm{~m}$ amplitude (Fig. 2). The average event mean 

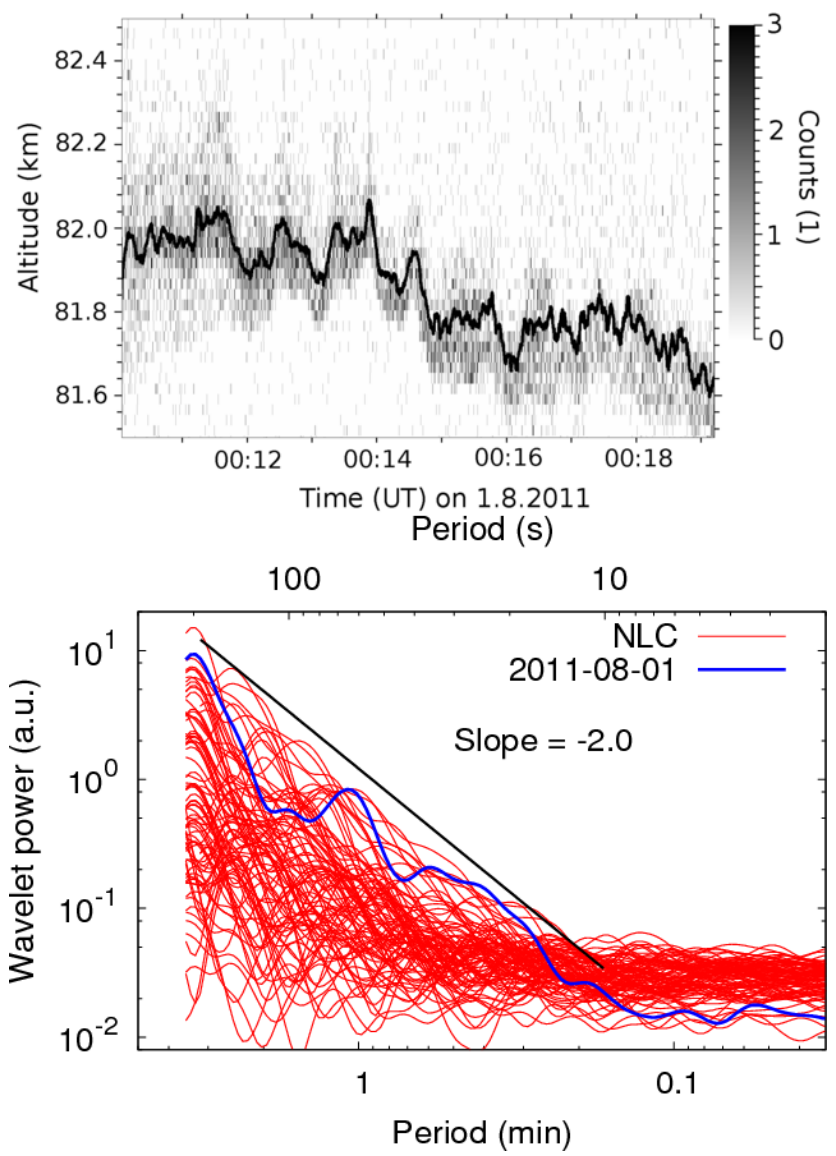

Fig. 9. Top: example lidar single-shot acquisition (LISA) raw data file, time resolution $0.33 \mathrm{~s}$ (10 shots) on 1 August 2011, 00:10:0400:20:10 UT. The black dots indicate the average NLC altitude smoothed by a $3.6 \mathrm{~s}$ (110 shots) window. Bottom: wavelet spectra of NLC altitude variations in 2011 (91 time series of 10 min duration each). The black line indicates a slope of -2 and the spectrum corresponding to the example shown is highlighted.

deviation is $0.2 \mathrm{~km}$ (Fig. 5b) and in the same order of magnitude as the variations on much larger timescales, for instance diurnal, seasonal and year-to-year variations. Fiedler et al. (2011, their Figs. 3 and 4) and Fiedler et al. (2009, their Fig. 3) found maximum variations from year to year up to $1.3 \mathrm{~km}$, variations with local time of $1.1 \mathrm{~km}$ and seasonal variation of $0.3 \mathrm{~km}$ (all peak to valley). The layer is moved up and down by both vertical winds and changes in temperature, which by destruction and re-formation makes the layer follow the cold phases of the waves. Rapp et al. (2002) showed by simulations with the CARMA model that, in general, GW with periods shorter than $6.5 \mathrm{~h}$ tend to destroy NLC. The periods observed here however are much shorter than the ones used in the simulation. They might be structures advected by the wind and resemble the ripples observed in $\mathrm{OH}$ airglow or NLC images. We note that we find periods shorter than about 5 min - the Brunt-Väisälä period which is the lower limit for internal GW - which might hint at external or acoustic waves in NLC. One example is shown in Fig. 9a. However, the wave period of GW can also be Doppler-shifted by large horizontal winds, making it difficult to regard such observations definitely as external or acoustic waves.

\subsection{Zonal transport of NLC}

Typical zonal wind speeds at NLC altitudes are $44 \mathrm{~m} \mathrm{~s}^{-1}$ (Fiedler et al., 2011). Assuming pure advection, observed wave periods of $20 \mathrm{~s}$ correspond to $800 \mathrm{~m}$ horizontal wavelength. Typical turbulent velocities are in the range of 1$3 \mathrm{~m} \mathrm{~s}^{-1}$, such that $20 \mathrm{~s}$ correspond to a $40 \mathrm{~m}$ scale, well within the inertial subrange (Lübken, 1997). The zonal wind that transports the NLC through the lidar beam leads to a mixture of spatial and temporal scales. The variations observed in the time domain can to some extent also be caused by spatial variations that are transported through the beam. Such variations can for example be imprinted by waves at earlier times. Assuming aligned quasi-monochromatic waves, the observed variations depend strongly on the orientation of wave fronts and wind speed. This must be kept in mind when analyzing observed wave periods. A full evaluation again requires additional spatial information of the NLC structures and detailed wind speeds, which can be obtained from satellite or ground-based photography and radars, respectively. For studies of such combined observations, we refer to Taylor et al. (2009) or Baumgarten et al. (2009, 2012).

\subsection{Implications for NLC brightness and relation to ground-based photography}

For an apparent maximum vertical velocity of $20 \mathrm{kmh}^{-1}$ ( $\widehat{=} 5.5 \mathrm{~m} \mathrm{~s}^{-1}$ ) that is reached at timescales of $2.5 \mathrm{~min}$ (Fig. 5), we estimate an adiabatic heating/cooling rate of $\pm 3.3 \mathrm{~K} \mathrm{~min}^{-1}$. Using the equations for radial growth of Hesstvedt (1961) and for the saturation vapor pressure of Rapp and Thomas (2006, Eq. 4), we expect maximum growth rates of $0.61 \mathrm{nmmin}^{-1}$ and $-1.39 \mathrm{nmmin}^{-1}$ at $152 \mathrm{~K}$ ambient temperature for a $47 \mathrm{~nm}$ sized ice particle (Baumgarten et al., 2008). Employing a $r^{6}$ dependence of the brightness $\beta$, this causes an increase of $+8 \% \mathrm{~min}^{-1}$ or $-17 \% \mathrm{~min}^{-1}$ in brightness. In the literature, mean vertical velocities on the order of $25 \mathrm{~cm} \mathrm{~s}^{-1}$ are reported, and variations up to $1 \mathrm{~m} \mathrm{~s}^{-1}$ with oscillation periods of 5 min (Balsley and Riddle, 1984; Woodman and Guillen, 1974). A measurable influence of such oscillatory motions on brightness can therefore be expected too.

In our lidar observations, the maximum backscatter $\beta_{\text {peak }}$ is caused mainly by the presence of large particles due to the high sensitivity to the radius of $\propto r^{6}$, and to number density (Baumgarten et al., 2008). The particle size determines the fall speed of the ice particles, moving them through different temperature regimes, inducing growth or sublimation. $\beta_{\text {int }}$ represents the total column brightness, such that a wide weak layer may have $\beta_{\text {int }}$ equal to a thin but bright 
layer. $\beta_{\text {int }}$ is sensitive to particle size as well as number density and it will be generally larger for a larger vertical extent of the saturation zone. Temporal brightness variations at short scales observed by lidar occur either due to temperature variations or spatial accumulation of large particles that may be caused by horizontal or vertical velocity variations leading to local confluence or diffluence (Fritts et al., 1993). Satellite and ground-based imagery often show distinct quasi-monochromatic wave patterns in NLC, as shown in Fig. 1. The brightness in images compares best to the column brightness $\beta_{\text {int }}$ measured by lidar (besides geometrical effects due to the observation at low elevation angles). Using typical zonal wind speeds, a period of $20 \mathrm{~s}$ measured by lidar converts to a horizontal wavelength $\lambda=800 \mathrm{~m}$. Modern high-resolution cameras allow for $10 \mathrm{~m}$ resolution at NLC altitude, which means that the waves observed by lidar can be observed by ground-based cameras, too, although the latter are restricted by daylight conditions at polar latitudes. In single events, the observation of quasi-monochromatic waves is common, for lidar observations of NLC as well as for NLC photography or $\mathrm{OH}$ airglow. As becomes evident by the analysis of the complete lidar dataset, the observation of quasimonochromatic wave patterns is common; however the wave period varies. We deduced significant periods in the temporal evolution of altitude as well as brightness features. Altitude variations are globally significant (per NLC event) between about $6 \mathrm{~min}$ to $1 \mathrm{~h}$, but only few globally significant periods in brightness variations are found. Analysis of the dataset from the single-shot acquisition system with a higher temporal resolution (summer 2011 only) indicates that periods down to $1 \mathrm{~min}$ are indeed existent and detectable.

\subsection{On GW spectra and spectral analysis of NLC parameters}

Sources of GW are mostly in the troposphere, mainly created by flow over orography or convection. While propagating upwards, GW are filtered by winds and influenced by changing temperature environments, leading to reflections or ducting. GW can travel large horizontal distances and interact with other waves. It has proven possible to trace waves at mesospheric altitudes back to tropospheric source regions (e.g. Eckermann and Marks, 1997; Gerrard et al., 2004; Suzuki et al., 2013). On average, however, the various sources, filtering and mixing leads to a canonical spectrum with a defined spectral slope as introduced by Fritts and VanZandt (1993) (see also Staquet and Sommeria (2002) and Fritts and Alexander (2003) for reviews of GW). GW spectra are usually evaluated in terms of vertical and horizontal velocity and temperature perturbations. Typically, spectral slopes close to $-\frac{5}{3}(=-1.67)$ are found for horizontal wind and temperature variations, while vertical wave number spectra exhibit slopes between -2 and -3 . A $k^{-5 / 3}$ dependence of power spectra is also observed for passive, scalar tracers transported by turbulent flow in the inertial subrange (Batchelor, 1959). Indeed our observations show a common average spectral slope. Although spectral peaks due to waves are common, no period seems to be preferred such that on average a mean slope is formed. The value of this spectral slope is steeper for altitude variations $(-2.0)$ than for brightness variations $(-1.4)$. For scales down to $10 \mathrm{~s}$ periods we found again spectral slopes up to -2 for altitude variations. Due to the fact that NLC altitude and brightness variations, because of growth times and horizontal transport, are not one-to-one correspondences to direct GW quantities mentioned above, we expect to see a mixture of the mentioned slopes. It can be speculated that the flatter slope of brightness variations occurs due to the slower growth of NLC particles compared to the timescales of the waves analyzed.

\section{Conclusions}

We have analyzed four years of ALOMAR RMR lidar data of NLC (a total of $2300 \mathrm{~h}$ ) at a high temporal resolution of $30 \mathrm{~s}$ with respect to small-scale structures in NLC. Variations in altitude as well as in brightness are considered.

- In accordance with ground-based imagery of NLC and airglow observations, we find that quasimonochromatic waves are common. No single period is preferred, but periods of prominent waves are between $1 \mathrm{~min}$ and $1 \mathrm{~h}$ for the time range analyzed here.

- For the first time, we evaluate a single-shot acquisition system that records data at $33 \mathrm{~ms}$ interval, i.e. five orders of magnitude higher time resolution than standard analysis. We show that fluctuations on scales of $1 \mathrm{~min}$ exist and spectral signatures can be observed down to periods of about $10 \mathrm{~s}$.

- Generally, we observe average spectral slopes of temporal brightness of $\alpha=-1.4$ and altitude variations of $\alpha=-2.0$, and in the case of LISA analysis also slopes up to -2 .

- Maximum amplitudes of variations of NLC altitudes are $2.3 \mathrm{~km}$. Average wave amplitudes of $0.2 \mathrm{~km}$ are comparable to seasonal variations.

- Apparent vertical velocities of about $2.2 \mathrm{~m} \mathrm{~s}^{-1}$ occur in a time window of $2.5 \mathrm{~min}$.

The extension of time resolution beyond $15 \mathrm{~min}$ and the analysis presented here prove the existence of detectable variations in NLC at timescales down to $1 \mathrm{~min}$ and, by employing typical horizontal wind speeds, relate those waves to the small-scale billows or ripples that are known from groundbased NLC photography. The interpretation of vertical movements, periods and spectral slopes, however, is complicated by the fact that temporal and spatial scales are mixed due to advection and microphysical changes of NLC particles. 
The importance of small-scale waves excited by breaking GW lies in the delivery of significant amounts of momentum to the MLT environment at high latitudes in summer. These processes affect the meridional circulation and thus lead to the extreme low temperatures allowing for NLC formation. Exactly this formation of NLC can again be used to monitor the dynamical processes that lead to its existence, in fact at various temporal and spatial scales. We show that NLC are suitable tracers for these small-scale waves, too. We plan to apply our results on systematic wave analysis studies, for example as a function of season and local time or regarding year-to-year variability. We also aim to study the combined effects of GW and turbulence on NLC.

Acknowledgements. We thank the staff of the ALOMAR station and several students for their support with lidar operations.

Edited by: M. Palm

\section{References}

Backhouse, T. W.: The luminous cirrus cloud of June and July, Meterol. Mag., 20, 133-133, 1885.

Balsley, B. B. and Riddle, A. C.: Monthly mean values of the mesospheric wind field over Poker Flat, Alaska, J. Atmos. Sci., 41, 2368-2375, 1984.

Balsley, B. B., Ecklund, W. L., and Fritts, D. C.: VHF echoes from the high-latitude mesosphere and lower thermosphere: observations and interpretations, J. Atmos. Sci., 40, 2451-2466, doi:10.1175/1520-0469(1983)040<2451:VEFTHL>2.0.CO;2, 1983.

Batchelor, G. K.: Small-scale variation of convected quantities like temperature in turbulent fluid. Part 1. General discussion and the case of small conductivity, Fluid Mech., 5, 113-133, doi:10.1017/S002211205900009X, 1959.

Baumgarten, G.: Doppler Rayleigh/Mie/Raman lidar for wind and temperature measurements in the middle atmosphere up to 80 km, Atmos. Meas. Tech., 3, 1509-1518, doi:10.5194/amt-31509-2010, 2010.

Baumgarten, G., Fiedler, J., Lübken, F. J., and von Cossart, G.: Particle properties and water content of noctilucent clouds and their interannual variation, J. Geophys. Res., 113, D06203, doi:10.1029/2007JD008884, 2008.

Baumgarten, G., Fiedler, J., Fricke, K. H., Gerding, M., Hervig, M., Hoffmann, P., Müller, N., Pautet, P.-D., Rapp, M., Robert, C., Rusch, D., von Savigny, C., and Singer, W.: The noctilucent cloud (NLC) display during the ECOMA/MASS sounding rocket flights on 3 August 2007: morphology on global to local scales, Ann. Geophys., 27, 953-965, doi:10.5194/angeo-27-953-2009, 2009.

Baumgarten, G., Chandran, A., Fiedler, J., Hoffmann, P., Kaifler, N., Lumpe, J., Merkel, A., Randall, C. E., Rusch, D., and Thomas, G.: On the horizontal and temporal structure of noctilucent clouds as observed by satellite and lidar at ALOMAR (69 N), Geophys. Res. Lett., 39, L01803, doi:10.1029/2011GL049935, 2012.
Blix, T., Thrane, E., and Andreassen, Ø.: In situ measurements of the fine-scale structure and turbulence in the mesosphere and lower thermosphere by means of electrostatic positive ion probes, J. Geophys. Res., 95, 5533-5548, 1990.

Chandran, A., Rusch, D. W., Palo, S. E., Thomas, G. E., and Taylor, M. J.: Gravity wave observations in the summertime polar mesosphere from the Cloud Imaging and Particle Size (CIPS) experiment on the AIM spacecraft, J. Atmos. Sol.-Terr. Phy., 71, 392-400, doi:10.1016/j.jastp.2008.09.041, 2009.

Chu, X., Espy, P. J., Nott, G. J., Diettrich, J. C., and Gardner, C. S.: Polar mesospheric clouds observed by an iron Boltzmann lidar at Rothera $\left(67.5^{\circ} \mathrm{S}, 68.0^{\circ} \mathrm{W}\right)$, Antarctica from 2002 to 2005 : properties and implications, J. Geophys. Res., 111, D20213, doi:10.1029/2006JD007086, 2006.

Dalin, P., Pertsev, N., Frandsen, S., Hansen, O., Andersen, H., Dubietis, A., and Balciunas, R.: A case study of the evolution of a Kelvin-Helmholtz wave and turbulence in noctilucent clouds, J. Atmos. Sol.-Terr. Phy., 72, 1129-1138, doi:10.1016/j.jastp.2010.06.011, 2010.

Eckermann, S. D. and Marks, C. J.: GROGRAT: a new model of the global propagation and dissipation of atmospheric gravity waves, Adv. Space Res., 20, 1253-1256, doi:10.1016/S02731177(97)00780-1, 1997.

Fiedler, J., Baumgarten, G., and Lübken, F.: NLC observations during one solar cycle above ALOMAR, J. Atmos. Sol.-Terr. Phy., 71, 424-433, doi:10.1016/j.jastp.2008.11.010, 2009.

Fiedler, J., Baumgarten, G., Berger, U., Hoffmann, P., Kaifler, N., and Lübken, F.-J.: NLC and the background atmosphere above ALOMAR, Atmos. Chem. Phys., 11, 5701-5717, doi:10.5194/acp-11-5701-2011, 2011.

Fritts, D. C. and Alexander, M. J.: Gravity wave dynamics and effects in the middle atmosphere, Rev. Geophys., 41, 1003, doi:10.1029/2001RG000106, 2003.

Fritts, D. C. and VanZandt, T. E.: Spectral estimates of gravity wave evergy and momentum fluxes. Part I: Energy dissipation, acceleration, and constraints., J. Atmos. Sci., 50, 3685-3694, doi:10.1175/1520-0469(1993)050<3685:SEOGWE>2.0.CO;2, 1993.

Fritts, D. C., Smith, S. A., Balsley, B. B., and Philbrick, C. R.: Evidence of gravity wave saturation and local turbulence production in the summer mesosphere and lower thermosphere during the STATE experiment, J. Geophys. Res., 93, 7015-7025, 1988.

Fritts, D. C., Isler, J. R., Thomas, G. E., and Andreassen, O.: Wave breaking signatures in Noctilucent Clouds, Geophys. Res. Lett., 20, 2039-2042, doi:10.1029/93GL01982, 1993.

Fritts, D. C., Isler, J. R., Hecht, J. H., Walterscheid, R. L., and Andreassen, $\varnothing .:$ Wave breaking signatures in sodium densities and $\mathrm{OH}$ nightglow 2, Simulation of wave and instability structures, J. Geophys. Res., 102, 6669-6684, doi:10.1029/96JD01902, 1997.

Fritts, D. C., Bizon, C., Werne, J. A., and Meyer, C. K.: Layering accompanying turbulence generation due to shear instability and gravity-wave breaking, J. Geophys. Res., 108, 8452, doi:10.1029/2002JD002406, 2003.

Galassi, M., Davies, J., Theiler, J., Gough, B., Jungman, G., Alken, P., Booth, M., and Rossi, F.: GNU Scientific Library Reference Manual, 3 edn., for version 1.12, Network Theory Ltd, UK, 2009.

Gardner, C. S. and Taylor, M. J.: Observational limits for lidar, radar, and airglow imager measurements of gravity wave parame- 
ters, J. Geophys. Res., 103, 6427-6437, doi:10.1029/97JD03378, 1998.

Gerrard, A. J., Kane, T. J., Eckermann, S. D., and Thayer, J. P.: Gravity waves and mesospheric clouds in the summer middle atmosphere: a comparison of lidar measurements and ray modeling of gravity waves over Søndrestrøm, Greenland, J. Geophys. Res., 109, D10103, doi:10.1029/2002JD002783, 2004.

Hecht, J. H.: Instability layers and airglow imaging, Rev. Geophys., 42, RG1001, doi:10.1029/2003RG000131, 2004.

Hecht, J. H., Liu, A. Z., Walterscheid, R. L., Franke, S. J., Rudy, R. J., Taylor, M. J., and Pautet, P.-D.: Characteristics of short-period wavelike features near $87 \mathrm{~km}$ altitude from airglow and lidar observations over Maui, J. Geophys. Res., 112, D16101, doi:10.1029/2006JD008148, 2007.

Hesstvedt, E.: Note on the nature of noctilucent clouds, J. Geophys. Res., 66, 1985-1987, doi:10.1029/JZ066i006p01985, 1961.

Hill, R., Gibson-Wilde, D., Werne, J., and Fritts, D.: Turbulenceinduced fluctuations in ionization and application to PMSE, Earth Planets Space, 51, 499-514, 1999.

Hoffmann, P., Rapp, M., Serafimovich, A., and Latteck, R.: On the occurrence and formation of multiple layers of polar mesosphere summer echoes, Geophys. Res. Lett., 32, L05812, doi:10.1029/2004GL021409, 2005.

Holton, J. R.: The influence of gravity wave breaking on the general circulation of the middle atmosphere, J. Atmos. Sci., 40, 2497-2507, doi:10.1175/15200469(1983)040<2497:TIOGWB>2.0.CO;2, 1983.

Hoppe, U.-P. and Fritts, D. C.: On the downward bias in vertical velocity measurements by VHF radars, Geophys. Res. Lett., 22, 619-622, doi:10.1029/95GL00165, 1995.

Hoppe, U.-P., Fritts, D., Reid, I., Czechowsky, P., Hall, C., and Hansen, T.: Multiple-frequency studies of the high-latitude summer mesosphere: implications for scattering processes, J. Atmos. Terr. Phys., 52, 907-926, 1990.

Jesse, O.: Auffallende Abenderscheinungen am Himmel, Meteorol. Z., 2, 311-312, 1885 .

Kaifler, N., Baumgarten, G., Klekociuk, A. R., Alexander, S. P., Fiedler, J., and Lübken, F.-J.: Small scale structures of NLC observed by lidar at $69^{\circ} \mathrm{N} / 69^{\circ} \mathrm{S}$ and their possible relation to gravity waves, J. Atmos. Solar.-Terr. Phy., 104, 244-252 doi:10.1016/j.jastp.2013.01.004, 2013.

Kelley, M., Ulwick, J., Röttger, J., Inhester, B., Hall, T., and Blix, T.: Intense turbulence in the polar mesosphere: rocket and radar measurements, J. Atmos. Terr. Phys., 52, 875-891, 1990.

Kiliani, J., Lübken, F.-J., Berger, U., and Baumgarten, G.: Trajectory modelling of mesospheric ice particles, in: EGU General Assembly Conference Abstracts, vol. 12 of EGU General Assembly Conference Abstracts, 10922-10922, 2010.

Klekociuk, A. R., Morris, R. J., and Innis, J. L.: First Southern Hemisphere common-volume measurements of PMC and PMSE, Geophys. Res. Lett., 35, L24804, doi:10.1029/2008GL035988, 2008.

Leslie, R. C.: Sky glows, Nature, 32, p. 245, doi:10.1038/032245a0, 1885.

Lübken, F.-J.: Seasonal variation of turbulent energy dissipation rates at high latitudes as determined by in situ measurements of neutral density fluctuations, J. Geophys. Res., 102, 1344113456, doi:10.1029/97JD00853, 1997.
Lübken, F.-J., Rapp, M., and Hoffmann, P.: Neutral air turbulence and temperatures in the vicinity of polar mesosphere summer echoes, J. Geophys. Res., 107, 2156-2202, doi:10.1029/2001JD000915, 2002.

Müllemann, A., Rapp, M., and Lübken, F.-J.: Morphology of turbulence in the polar summer mesopause region during the MIDAS/SOLSTICE campaign 2001, Adv. Space Res., 31, 20692074, doi:10.1016/S0273-1177(03)00230-8, 2003.

Nielsen, K., Taylor, M. J., Hibbins, R. E., and Jarvis, M. J.: Climatology of short-period mesospheric gravity waves over Halley, Antarctica $\left(76^{\circ} \mathrm{S}, 27^{\circ} \mathrm{W}\right)$, J. Atmos. Sol.-Terr. Phy., 71, 9911000, doi:10.1016/j.jastp.2009.04.005, 2009.

Pautet, P.-D., Stegman, J., Wrasse, C. M., Nielsen, K., Takahashi, H., Taylor, M. J., Hoppel, K. W., and Eckermann, S. D.: Analysis of gravity wave structures visible in noctilucent cloud images, J. Atmos. Sol.-Terr. Phy., 73, 2082-2090, doi:10.1016/j.jastp.2010.06.001, 2010.

Pfrommer, T., Hickson, P., and She, C.-Y.: A large-aperture sodium fluorescence lidar with very high resolution for mesopause dynamics and adaptive optics studies, Geophys. Res. Lett., 361, L15831, doi:10.1029/2009GL038802, 2009.

Rapp, M. and Lübken, F.-J.: Polar mesosphere summer echoes (PMSE): Review of observations and current understanding, Atmos. Chem. Phys., 4, 2601-2633, doi:10.5194/acp-4-2601-2004, 2004.

Rapp, M. and Thomas, G. E.: Modeling the microphysics of mesospheric ice particles: assessment of current capabilities and basic sensitivities, J. Atmos. Sol.-Terr. Phy., 68, 715-744, doi:10.1016/j.jastp.2005.10.015, 2006.

Rapp, M., Lübken, F., Müllemann, A., Thomas, G., and Jensen, E.: Small scale temperature variations in the vicinity of NLC: experimental and model results, J. Geophys. Res., 107, 4392, doi:10.1029/2001JD001241, 2002.

Rapp, M., Strelnikov, B., Müllemann, A., Lübken, F.-J., and Fritts, D. C.: Turbulence measurements and implications for gravity wave dissipation during the MaCWAVE/MIDAS rocket program, Geophys. Res. Lett., 31, L24S07, doi:10.1029/2003GL019325, 2004.

Staquet, C. and Sommeria, J.: Internal gravity waves: from instabilities to turbulence, Annu. Rev. Fluid Mech., 34, 559-593, doi:10.1146/annurev.fluid.34.090601.130953, 2002.

Suzuki, S., Lübken, F.-J., Baumgarten, G., Kaifler, N., Eixmann, R., Williams, B. P., and Nakamura, T.: Vertical propagation of a mesoscale gravity wave from the lower to the upper atmosphere, J. Atmos. Sol.-Terr. Phy., 97, 29-36, doi:10.1016/j.jastp.2013.01.012, 2013.

Taylor, M. J., Zhao, Y., Pautet, P., Nicolls, M. J., Collins, R. L., Barker-Tvedtnes, J., Burton, C. D., Thurairajah, B., Reimuller, J., Varney, R. H., Heinselman, C. J., and Mizutani, K.: Coordinated optical and radar image measurements of noctilucent clouds and polar mesospheric summer echoes, J. Atmos. Sol.-Terr. Phy., 71, 675-687, doi:10.1016/j.jastp.2008.12.005, 2009.

Torrence, C. and Compo, G. P.: A practical guide to wavelet analysis, B. Am. Meteorol. Soc., 79, 61-78, doi:10.1175/15200477(1998)079<0061\%3AAPGTWA>2.0.CO\%3B2, 1998.

Tsuda, T. T., Nozawa, S., Kawahara, T. D., Kawabata, T., Saito, N., Wada, S., Hall, C. M., Oyama, S., Ogawa, Y., Suzuki, S., Ogawa, T., Takahashi, T., Fijiwara, H., Fujii, R., Matuura, N., and Brekke, A.: Fine structure of sporadic sodium layer observed 
with a sodium lidar at Tromso, Norway, Geophys. Res. Lett., 38, L18102, doi:10.1029/2011GL048685, 2011.

Turco, R. P., Toon, O. B., Whitten, R. C., Keesee, R. G., and Hollenbach, D.: Noctilucent clouds - simulation studies of their genesis, properties and global influences, Planet. Space Sci., 30, 11471181, doi:10.1016/0032-0633(82)90126-X, 1982.

von Zahn, U., von Cossart, G., Fiedler, J., Fricke, K. H., Nelke, G., Baumgarten, G., Rees, D., Hauchecorne, A., and Adolfsen, K.: The ALOMAR Rayleigh/Mie/Raman lidar: objectives, configuration, and performance, Ann. Geophys., 18, 815-833, doi:10.1007/s00585-000-0815-2, 2000.

Wickwar, V. B., Taylor, M. J., Herron, J. P., and Martineau, B. A.: Visual and lidar observations of noctilucent clouds above Logan, Utah, at $41.7^{\circ} \mathrm{N}$, J. Geophys. Res., 107, 1-7, doi:10.1029/2001JD001180, 2002.
Witt, G.: Height, structure and displacements of noctilucent clouds, Tellus, 14, 1-18, 1962.

Woodman, R. F. and Guillen, A.: Radar observations of winds and turbulence in the stratosphere and mesosphere, J. Atmos. Sci., 31, 493-505, doi:10.1175/15200469(1974)031<0493:ROOWAT>2.0.CO;2, 1974.

Yamada, Y., Fukunishi, H., Nakamura, T., and Tsuda, T.: Breaking of small-scale gravity wave and transition to turbulence observed in OH airglow, Geophys. Res. Lett., 28, 2153-2156, doi:10.1029/2000GL011945, 2001. 